\title{
Towards a Framework for Knowledge Democracy
}

\author{
Rajesh Tandon and Budd Hall
}

This collection of writings, based on practices around the world, has described a wide range of meanings and features of social responsibility of higher education. These features may be locally constructed in a university or Higher Education Institution (HEI), or they may characterise a country and/or region of the world. Taken together, these features constitute a new, more inclusive and robust framework of social responsibility in higher education, which are even more important in the post-pandemic global order. This approach to understanding the meanings of social responsibility and how they can be put into practice are framed within a framework of knowledge democracy, a comprehensive and organic approach to understanding the role of knowledge that transcends the limits of earlier concepts of knowledge economy and knowledge society.

Key features of socially responsible higher education includes elements such as:

- Recognition of diversities of knowledge systems and epistemologies

- Coherence and integration of teaching, research and engagement missions

- Contextually responsive, locally rooted, place based and linguistically plural

- Socially inclusive, seeking diversity amongst students and academics

- Pluriversality replacing universality

- Transcending rankings

- Reclaiming the purpose of higher education as a public good

These features, taken together, are advancing the prevalent discourse on social responsibility of higher education. They complement elements shared in the several aspects of the Introduction to the book. This set of principles strengthens a new, more societally oriented, knowledge democracy perspective on social responsibility of higher education. In the emerging aftermath of COVID19, such a knowledge democracy perspective is required to re-position and realign higher education institutions, policies and systems around the world.

Production, dissemination, teaching and promotion of knowledge is at the core of higher education. Each HEI performs its knowledge functions in its own

(C) RAJESH TANDON AND BUDD HALL, 2021 | DOI: 10.1163/9789004459076_024 This is an open access chapter distributed under the terms of the CC BY-NC 4.0 License. 
unique way, though national standards, international templates and disciplinary domains tend to tightly specify what is meant by knowledge (scientific?), knowledge production (research?), knowledge dissemination (teaching, publishing, conferencing, etc.?).

Central to the new discourse on social responsibility of HEIs is the recognition, appreciation and valuing of diversity of knowledges, their underlying epistemologies (ways of knowing) and knowledge cultures (norms, values, principles). Historically, the higher education community has defined academic knowledge as only valid, scientific knowledge. Acknowledgement of multiple sites and forms of knowledge is now beginning to be recognised (Tremblay et al., 2015). Respect for such diversity has been reinforced by several chapters in this collection, from a wide diversity of contexts and experiences.

Padayachee et al., in their essay, provide an exploration of a system of higher education based on the African philosophy of Ubuntu:

African indigenous knowledge systems are community-based knowledge systems that members of a culturally specific community have developed and used for centuries for shared livelihood and sustainability $[\cdots]$.

According to this holistic paradigm, the creation of a better society entails developing the individual along natural and ethical lines within the context of the collective, a vision embodied in the spirit of Ubuntu, which includes caring for one another's well-being with mutual support in ways that demonstrate that people are people through other people.

Comparing this African perspective with that of Gandhi, they suggest that Gandhi evolved his philosophy of learning - where head, heart and hands are united - when he lived in South Africa. According to Gandhi, a person was made of three constituents - the body, mind and spirit - and, thus, education must lead to a holistic development of the body, mind and spirit (UNEsco Chair, 2019). His perspective on education through life, in everyday life, resonates with Ubuntu's emphasis on coherence between people, nature and human solidarity. In a similar vein, Nobel laureate Rabindranath Tagore proposed an intimate inter-linkage between the everyday life and livelihood of local rural communities and teaching-learning of students. In her chapter, Anand communicates this differential and unique perspective in founding thesis of the university - Shantiniketan - set up by him:

If a true school is to be founded in India, the school must be from the beginning group. The School will make use of the best methods in 
agriculture, the breeding of livestock and development of village crafts. The teachers, students and people of the surrounding countryside will be related to each other with the strong and intimate ties of livelihood. They shall co-operate to produce all the necessities of their own existence.

In analysing the relationship between Nepali society and the colonial system of higher education, Regmi takes a 'lifeworld' approach in his chapter:

The disconnection at the cultural level is caused by the neglect of knowledge production function of the lifeworld. The lifeworld provides each member of the society with the stock of knowledge that they can use for social interaction. This stock of tacit knowledge "is not the knowledge generated by a single human subject". Social responsibility of the Nepali higher education system is to value local rural-agricultural 'tacit' knowledge.

Promotion of 'sejahetra' is the purpose of education in Malaysia, and higher education can be socially responsible by accelerating the learning and practice of 'sejahetra' by youth, as Muzaimi et al. describe in their chapter:

'Sejahtera' is a Malay phrase that carries multiple meanings - peace, tranquillity, harmony, wellness and health - viewed in this concept collectively by USM as a balanced living from aspects of spiritual, physical, intellectual, cultural, ethics, economics, as well as environmental, so as to produce and sustain a balanced society.

While analysing the experiences of higher education institutions in Argentina, Fuentas has demonstrated the perspective and methodology of psychomotricity, and explains the same as providing an alternative epistemology:

In those PVU projects the community and the territory work as a space of artisan training dialogue with the same native perspective of psychomotricity at UNTREF, in which it is not a matter of applying techniques for the solution of individual problems, but a space of interaction and regulation and exchange of knowledge and power, where uncertainty, misunderstandings, procrastination, and dialogue, meetings and presence and listening are fundamental.

As can be seen from the above, each society has its own diverse meanings and concepts related to knowledge, its purposes and praxis. Ubuntu in East and Southern Africa, sejahetra in Malaysia, psychomotricity in Argentina, Tagore's 
education from life and Gandhi's emphasis on knowledge from rural society are all different manifestations of the same message - higher education can act socially responsible by integrating and co-producing multiple forms of knowledge through respect for diverse epistemologies.

As it has been witnessed through the pandemic, science is not omniscient. Going forward, there is a need to respect and mobilise the various knowledge systems (UNESCO Chair, 2020). In the aftermath of Covid-19, multiple epistemologies may indeed have much greater relevance to human life than acknowledged before.

\section{Coherence and Integration of Teaching, Research and Service} Missions

Institutional design, faculty role allocations and resourcing patterns of HEIs since the second World War resulted in the fragmentation of functions and structures serving the three core missions - teaching, research and service - of a university, leaving them disconnected with each other.

Some departments and centres focus on research; some faculty (mostly junior or graduate students) are assigned teaching responsibilities; and public engagement tasks linked to service to society are either 'out-sourced' to a partner or performed through extension departments. Teaching generally happens in the classroom, research in labs and service over weekends or during holidays.

Socially responsible higher education demonstrates the integrated nature of teaching, research and service, through actual practice. Students make meaningful contributions to societal needs while learning and gaining credits for the same. Faculty members are able to integrate enquiry while teaching students in the real world.

Students gain satisfaction that their competencies are helping society. In the process, they improve their learning through contextual theorising. Thinking and doing are not artificially separated, but carry on simultaneously.

Those assigned the task of public engagement and service to society are not ghettoised in a corner or basement or faculty or discipline. Social workers alone need not be assigned such tasks; physicists too can be 'engaged' with society around them.

Several chapters in this collection have highlighted the significance of this integrated approach through the practices followed in their HEIs. In illustrating this approach in Javierana University, Cali (Colombia), Morales and Motta have demonstrated the value of FORJA, which integrates disciplinary 
knowledge with local communities of the region. This approach to service learning has been integrated now in 18 faculties of the university already. According to their principle of integration:

Training process needs to create conditions that allow students and teachers to confront theoretical concepts with reality, establish personal relationships with different participants in the territory and be nourished by experiences that claim rights and that are based on human dignity.

While all HEIs may not be able to integrate such an approach institution-wide, other examples demonstrate the widespread relevance and impact of this approach in a diversity of disciplines and teaching programmes. Moolman and McMillan have given a critical example of this approach in the Faculty of Engineering at the University of Cape Town (South Africa), which has built a course that takes students to interact with cities, neighbourhoods and communities in a segregated society:

Inherent in the framing of the course is the understanding that students are present in three intersecting identities: as a student, as an emerging professional and as an active citizen. A decolonial lens requires a different understanding of citizenship and way of structuring learning and being.

In the case from Montenegro, Stojanović, in her chapter of this book, clearly describes a similar integrated approach for the Faculty of Visual Arts:

The idea was to reach learning outcomes defined by the curricula of the course by partaking inactivities outside the traditional classroom and identifying and solving community problems. In that way, students would become more active citizens who not only take all the advantages and benefits from the society, but also contribute to its welfare. It was assumed that participating in such an activity would improve students' practical, communication, soft, organizational and leadership skills, as well as create a more dynamic, interesting, creative, challenging and motivating atmosphere for learning process.

Learning, teaching and service are, thus, organically integrated, involving students, faculty and the community, in Montenegro.

Likewise, Sepúlveda Maulén describes the experiences of Instituto Professionalo (IP) in Chile, where the practice of service-learning (SL) is beginning to 
be institutionalised in a manner that is substantially linked to students' learning from and with communities:

One of the challenges is to respond to train people who are responsible and committed to their environment. Social responsibility in HEIs opens a space for reflection on how institutions are territorially inserted into their communities, aimed at a horizontal relationship and mutual collaboration and learning.

Thomas Farnell's chapter in the book outlines a framework of community engagement in the European context that derives some of its practices from Croatia; it highlights the integrated and contextually embedded nature of teaching, research and engagement.

Socially responsible higher education, in this integrated approach to its core functions, may create major realignments institutionally. Such an institutional realignment may create coherence for students, academics as well as communities. Holistic and coherent curricula, engaged and practical pedagogy and meaningful and usable research functions of a HEI may thus undergo systemic design. Linguistically Plural

An important facet of social responsibility of higher education is its contextual responsiveness. All institutions derive meaning of their purposes in a contextually responsive manner. Institutional culture is deeply influenced by local culture, even if it is designed to be insular. For most responsiveness, context matters. In HEIs, what is taught, what is researched and what is served derive purpose from being responsive to the context. A university located in a mountainous region should be teaching geography and hydrology differently than one located near the ocean. Management education in a country with twothirds of the workforce in small businesses should be undertaking research and teaching programmes predominantly covering small business ecosystem.

Several chapters in this collection bring out nuances of such a contextually responsive nature of higher education. In examining social responsibility of higher education in Peru, for example, Bregaglio et al. highlight the provisions of the New University Act (2014):

Pluralism, inclusion, intercultural dialogue and commitment to the country's development are the guiding principles of higher education, 
and universities should strive to interact with the community and engage in socially relevant teaching and research.

However, most legal education in Peru has focussed only on providing the service of 'free legal aid' through legal clinics, a methodology they learnt from American universities and have been practicing since the $198 \mathrm{os}$. The new Act demands a contextually responsive higher education, and Law Schools in Peru could take up more urgent public interest matters, as the authors point out:

Considering the number of human rights issues that urgently need to be addressed in Peru - ranging as wide as the prison system, the protection of LGBT + rights, adequate recognition of the right to identity - we would posit that law schools should aim towards establishing public interest clinics.

Given the vast indigenous population in Peru, with a long history of displacement from their natural resources, it is also noteworthy that laws that affect indigenous communities, as well as indigenous legal systems, are not really the focus of teaching and research in Peru. While the new Act creates the mandate for a contextually responsive higher education, Peru's law schools have yet to embrace it more fully. This is an interesting case, where national policy is far more supportive of socially responsible higher education, while actual practice of curriculum, pedagogy and research are yet to operationalise the same in both letter and spirit.

In a similar vein, the chapter on the National Law University system in India provides some examples of how students and faculty are providing legal aid and public interest research on issues of relevance to their local contexts.

Reliance on European languages for higher education has been a major instrument of colonisation of knowledge systems and world views. Even today, several countries (like Uganda) officially de-recognise any teaching and research in higher education if it is not conducted in English. Many decades ago, Gandhi argued that local languages must be the basis of learning and education, even in higher education. Witnessing the increasing homogenisation of cultures, lifestyles and thoughts, Gandhi had cautioned the country against this trend and urged for the popularisation of not just mother tongue scholarship, but also of vernacular thoughts and actions. He highlighted the need to revive the languages that belonged to the masses and which defined them (UNEsco Chair, 2019).

Language of teaching and research can significantly shift the composition and participation of students in higher education, making it more accessible 
and usable. Krawchenko et al., in their chapter, have described the local disconnect in Kyrgyzstan during the Soviet era, where the medium of admission and instruction was Russian language only, thereby excluding a large percentage of local youth population. Recent changes to admission and teaching in local language has now resulted in rapidly expanded higher education system of Kyrgyzstan. However, the curriculum and pedagogy have not been localised, resulting in further disconnect:

In a country where agriculture is the largest employer, universities graduate just $3 \%$ students in agriculture and veterinary sciences.

In contrast, the University of Central Asia in Kyrgyzstan is located in a poor region, uses local language for student recruitment and teaching, and has mandated community engagement for student learning and research. As a result, it is able to act in a socially responsible and locally respected manner.

The most significant shift towards local language in a higher education system happened in Qatar recently. Describing this shift in the chapter, Belkhiria et al. have narrated a powerful story of recent shift to Arabic (from English) as the medium of admission, teaching and research in Qatar University across all disciplines and faculties, other than science and engineering. As the analysis presented in their essay has demonstrated, in less than 5 years of the shift to Arabic language, the percentage of local Qatari students increased substantially. In addition, the authors argue that:

Promoting Arabic as the language of learning and teaching throughout all educational stages will allow students to "build a linguistic reservoir" that is essential to knowledge production, internalisation of social and cultural values, and the preservation of identity.

From this vantage point, Qatari experience shows that use of local languages in teaching and research can demonstrate social responsibility in many profound ways:

Hence, educational institutions have a vital role in sustaining such missions, especially in areas that cultivate social responsibility, identity formation and cultural development, in addition to academic success in the native languages.

The significance of locally rooted and linguistically plural higher education as socially responsible education is further illustrated from the experiences 
of Francophone African countries. Critiquing English language journals as the sole source of metrics for comparing citations of research, Piron et al. have described, in great detail, the hegemonic and exclusionary control over research in sub-Saharan African countries in their chapter. Describing some innovations to transcend such control, they provide an interesting illustration:

In this environment, a Francophone African platform of open access journals has just been created. The Grenier des savoirs is a platform that brings together 15 multidisciplinary journals, focusing on themes of importance to sub-Saharan Francophone Africa.

This network's editorial policies include commitment to translate and publish in local African languages and an assessment of research from the vantage point of its 'social relevance' (to be assessed by a group of concerned citizens, not domain experts or academics).

This approach, rooted in local language and culture, to academic research and knowledge dissemination is a manifestation of socially responsible higher education.

As several authors have highlighted, socially responsible higher education is contextually responsive and locally rooted. Its curriculum, pedagogy, themes and methods of research and priorities for service are responsive and relevant to local contexts, communities and society. Additionally, social responsibility of higher education is further enhanced if the languages of teaching, writing, research and communication are pluralistic, including locally and culturally prevalent ones. International comparative education and global theories are not dismissed; neither are European languages excluded. But, locally articulated theories, in local idioms, concepts and languages are recognised, valued and then integrated.

Another key principle of socially responsible higher education is the nature of inclusion it seeks to value and promote. Deviating from the historical role of the university as 'producer' of society's elites, a contemporary socially responsible system of higher education makes special efforts to embrace, value and facilitate diversity of perspectives, communities of experiences, as reflected in the student body, teaching and research staff, and societal engagement so promoted.

Recognition of diversity and social inclusion in higher education is not merely an instrumental arrangement; social inclusion of diversity is acknowledged as 
providing the impetus to responsible teaching and research. Several chapters in this collection have presented both theoretical and empirical materials in support of such a renewed and inclusive meaning of social responsibility.

Examples of inclusive enrolment and curriculum by changing the language of higher education away from European-colonial imposition to locally practiced, everyday languages have been provided in the previous section. Both Kyrgyzstan and Qatar stories demonstrate, albeit in rather different contexts, how shifting policy and practice to local languages as the medium of admission and teaching resulted in hugely inclusive admission and better academic performance by local students, who had otherwise missed out.

Likewise, in analysing the criteria for assessment of academic scholarship, Piron et al. have proposed a system which does not impose Euro-American metrics on African scholars:

The concept of such a polycentric system is not difficult to understand. The scholarly community of the United States of America, if they wish to, can keep the impact factor system for their journals, since it reflects their reality. It should not prevent the French-speaking scholarly community, the Spanish-speaking one or the Chinese-speaking one to create a quality assessment system for their journals that is more appropriate to their needs, their languages, their contexts and their research concerns, one that could cover any discipline, not only social and human sciences. In Africa, $[\ldots]$ the different scholarly communities should be able to create several quality assessment systems that will respond to their needs, concerns and languages.

Diversity of assessment frameworks, thus, would lend local societal relevance to academic efforts, making it more feasible and incentivised for practice.

Several chapters in this collection have examined diversity and inclusion from the perspective of students. In analysing the French higher education system, Baurès and Lefébure argue that the new legislation in 2009 brought a distinctive emphasis on diversity and social inclusion

In France, since 2009, Article 55 of the Grenelle-1 Law of 2009, implementing the Grenelle agreements on environment, encourages HEIs to implement a SD \& SR approach through a "Green Plan". To this end, the Green Plan has led in 2010 to the SD \& SR frame of reference (FoR), a steering tool designed by the Conférence des Présidents d'Universités (CPU), the Conférence des Grandes Ecoles (CGE) and the REseau Français des Etudiants pour le Développement Durable (REFEDD). 
In analysing the experiences of the EHSP School of Public Health within the above perspective, the authors define this approach to diversity and inclusion in practical terms:

The school is currently working on the implementation of a 'diversity' action plan, in order to promote openness to all forms of diversity and, thus, contribute to the reduction of social and cultural inequalities. A working group on diversity, composed, among others, of all officers in charge of diversity issues (secularism and the fight against radicalisation, equal opportunities, gender equality, disability, etc.).

Another illustration of social inclusion comes from Ukraine, where the inclusion of disability is mainstreamed in a socially responsible manner. In their chapter, Nahirna and Mykhailyshyn have described the origins and practices of the Emmaus Centre within the university as a place for inclusion of disability in everyday academics:

This chapter gives an overview of the unique experience of the Ukrainian Catholic University, which, with the help of the Emmaus Centre of Support for People with Special Needs, welcomed people with intellectual disabilities into its educational milieu as professors of human relationships.

The strategy of the Ukrainian Catholic University for 2020-2025 with a selfrevealing title, "The University that Serves", very clearly and concisely proclaims that social responsibility is to begin within its walls with the experience of servitude and 'being with' those who are 'weaker'.

Another illustration comes from Germany, where Berg describes the inclusion of Syrian refugees as students in higher education institutions:

At some HEOS, the contact between international offices and diversity management increased significantly as a result of their common engagement with refugees.

However, the practice of inclusion was not uniform across Germany. With some new public support funds, Berg believes that more would happen in the coming years:

It can be expected that the landscape of refugee support will grow increasingly diverse, addressing combined questions of social integration, diversification, study preparation and internationalisation. 
A common theme in social inclusion of students and academics is 'moving beyond educating the elites'. Social inclusion is achieved not merely through national policies, but also through deliberate efforts inside each institution. Many cases in this collection have demonstrated the need for both policy support and strong leadership of institutions of higher education. As has been argued in these chapters above, social inclusion is not merely a social charity, but an integral component of strategy to enhance the quality of learning and research in higher education. Inclusion of hitherto excluded experiences, perspectives and knowledge capacities makes higher education systems more robust and resilient, a critical feature for post-CoviD institutional designs.

\section{$5 \quad$ Pluriversalism Replacing Universalism}

A significant aspect of this new framework of social responsibility of higher education is recognition, appreciation and valuing of the pluriversal character of teaching, research and service. By calling it a university, there seems to be an emphasis, howsoever hidden, on universal nature of curriculum, teaching, research and faculties. The emphasis on universal tends to make higher education homogenous in concepts and theories, underlying world views, epistemologies and knowledge, disciplines and structures of admission, certification, graduation and accreditation.

These tendencies towards a 'universal' nature of higher education have given rise to international comparisons. Various forms of national and international ranking systems have been created to measure the performance of higher education institutions. As authors of the chapter on rankings have argued, such a system of ranking is actually causing higher education to become increasingly irrelevant to society. Rankings are imposing further homogeneity, which is neither existent, nor feasible, least of all desirable.

Not only do rankings tend to attempt false comparisons, the metrics are biased in favour of western knowledge systems, European institutional designs and American models of quality benchmarks, like publications in English language journals, intellectually and materially controlled through a small domain elite, located in such elite institutions. The author of this chapter in this volume, who identifies itself as University Wankings, argues:

However, there is a fundamental fault line running through this assertion, in that rankings articulate a singular, universal model of 'good' which provides a particular kind of university and a specific social group with leading status and an unassailable advantage. [...] 
Global university rankings can then be seen as an act of white supremacy in that they systematically establish and preserve the dominance of a tiny selection of elitist universities in the white majority global North. Those 'top' universities, too, are predominantly white, in terms of their staff and students, due to their particular positions within those countries.

Therefore, socially responsible higher education institutions are diverse in design, structure, models and methodologies, which are responsive to diversity of contexts, communities, ecologies and challenges. Rankings make universities socially irresponsible, in that they tend to disconnect with local context, language, knowledge and culture.

Higher Education for Public Good

In order to understand and encourage the use of this framework of social responsibility of higher education, it is important to return to the basic question: what is the purpose of higher education in society? If the answer to that question is to promote personal fulfilment, human capital and talent development, preparation and supply for global labour market, and produce research and innovation to fuel the knowledge economy, then this framework will not be very appropriate, indeed. It is this very neoliberal, commercialisation of higher education systems around the world that propelled and justified rankings, gradings and the resultant homogenisation, one-size-must-fit-all!

How far will this commercial knowledge economy model travel? The current pandemic has shaken its roots. International student mobility, and resultant recruitment of fancy, fees paying international students, are unlikely to privilege universities of North America, Europe and Australia, in the future. Globalisation, in its current form, is already shaken. Preparation of knowledge solutions and talent for local economy and society is likely to be the 'new normal'. The present 'scientific' paradigm of instrumental rationality treated ecological contexts as 'unlimited resources to be exploited forever'. The colonial project deliberately 'killed' local, indigenous and diverse knowledge systems and epistemologies. That journey of epistemicide is now haunting humanity, and COVID-19 is an imminent manifestation of this phenomenon. As stated by Hall and Tandon (2020),

If the futures of education are to promote universal learning to become, then education has to be seen as serving the public and the well-being of 
humanity as a whole. [...] It is the public purpose of education alone that will prepare humanity for sustainable futures. Such a commitment to the public purpose of education needs to be societally embedded and not merely dwell amongst 'educationists' alone. The perspectives and principles of knowledge democracy will help to embed this societal commitment in the futures of education.

It is time that all societies begin to 'reclaim' the public purposes of higher education. It is important to 're-set' knowledge within a public knowledge common, where respect and transparent sharing of knowledge happens in non-academic and academic, Indigenous and non-Indigenous, and intersectional contexts; where knowledge plays a transformative and active role for the benefit of the public good. It is time that teaching/learning, research/ knowledge and service to society are aligned to a common goal of well-being of all people. In this 'refresh' lies the seed for re-imagining socially responsible higher education locally, and globally.

\section{References}

Hall, B., \& Tandon, R. (2020). Knowledge democracy: Opening our doors to all knowledge systems. Humanistic Futures of Learning, UNESCO. https://unesdoc.unesco.org/ ark:/48223/pfoooo372577/PDF/372577eng.pdf.multi

Tremblay, C., Hall, B., \& Tandon, R. (2015). Strengthening community university research partnerships: Global perspectives. University of Victoria Press and PRIA Press.

UNESCO Chair. (2019). Educating the mind, body \& heart: International dialogue on Gandhi \& Higher Education today. http://unescochair-cbrsr.org/pdf/educating the_mind_body_and_heart.pdf

UNESCO Chair. (2020). Community based participatory research and the pandemic: Today and tomorrow (Webinar). http://unescochair-cbrsr.org/pdf/resource/ Community_based_participatory_research_and_the_pandemic_Report.pdf 
Rajesh Tandon and Budd Hall - 9789004459076 Downloaded from Brill.come4/26/2023 06:38:37AM via free access 